\title{
BMJ Open Ethnic differences in cardiovascular morbidity and mortality among patients with breast cancer in the Netherlands: a register-based cohort study
}

\author{
Laura Deen, ${ }^{1,2}$ Josefien Buddeke, ${ }^{3}$ Ilonca Vaartjes, ${ }^{3}$ Michiel L Bots, ${ }^{3}$ \\ Marie Norredam, ${ }^{2,4}$ Charles Agyemang ${ }^{1}$
}

To cite: Deen L, Buddeke J, Vaartjes I, et al. Ethnic differences in cardiovascular morbidity and mortality among patients with breast cancer in the Netherlands: a registerbased cohort study. BMJ Open 2018;8:e021509. doi:10.1136/ bmjopen-2018-021509

- Prepublication history for this paper is available online. To view these files, please visit the journal online (http://dx.doi. org/10.1136/bmjopen-2018021509).

Received 20 January 2018 Revised 11 May 2018 Accepted 7 June 2018
Check for updates

(C) Author(s) (or their employer(s)) 2018. Re-use permitted under CC BY-NC. No commercial re-use. See rights and permissions. Published by BMJ.

For numbered affiliations see end of article.

Correspondence to Dr Charles Agyemang; c.o.agyemang@amc.uva.nl

\section{ABSTRACT}

Objectives Cardiovascular disease (CVD) is of increasing concern among breast cancer survivors. However, evidence on ethnic differences in CVD among women with breast cancer is sparse. We assessed ethnic differences in cardiovascular morbidity and mortality among patients with breast cancer in the Netherlands.

Methods A nationwide register-based cohort study comprising all women with a first admission for breast cancer ( $n=127714$ ) between 1996 and 2010 in the Netherlands was conducted. Differences in CVD admission, CVD mortality and overall CVD event, which comprised a CVD admission and/or CVD mortality, between the largest ethnic minority groups (Surinamese, Moroccan, Turkish, Antillean and Indonesian) and the Dutch general population (henceforth, Dutch) were investigated using Cox proportional hazard models.

Results The incidence of cardiovascular outcomes varied by the ethnic group. The incidence of an overall cardiovascular event was significantly higher for women with breast cancer from Suriname (HR 1.46; $95 \% \mathrm{Cl}$ 1.29 to 1.64) and Turkey (HR 1.25; 95\% Cl 1.03 to 1.51 ), compared with Dutch women with breast cancer. In contrast, Indonesian women with breast cancer had a significantly lower risk (HR $0.88 ; 95 \% \mathrm{Cl} 0.81$ to 0.96 ) of a cardiovascular event compared with Dutch women with breast cancer. The risk of a cardiovascular event did not differ between Moroccan and Dutch women with breast cancer, whereas for Antillean women the risk was not significantly higher.

Conclusions Our findings suggest that Surinamese and Turkish women with breast cancer are disadvantaged in terms of cardiovascular outcomes compared with Dutch women with breast cancer. More work is needed to unravel the potential factors contributing to these differences.

\section{INTRODUCTION}

Due to earlier diagnosis and more effective treatment, the survival rate among patients with breast cancer has now improved, resulting in a growing population of breast cancer survivors. In the Netherlands, the 5-year age-standardised survival rate has
Strengths and limitations of this study

- The study builds on data from nationwide registries which resulted in a large sample size.

- The validity of the linkage of the included registries has proved to be high.

- Although the study is based on a nationwide cohort of patients with breast cancer, absolute numbers are somewhat small when divided into different ethnic groups.

- Data on cardiovascular disease risk factors, such as smoking, alcohol and obesity, were not available since the study builds on registry data.

increased from $80 \%$ in $1995-1999$ to $85 \%$ in 2005-2009. ${ }^{1}$ With breast cancer becoming a curable disease, comorbidities and death from other conditions among breast cancer survivors are of increasing concern.

One of the most important comorbidities to consider in women with breast cancer is cardiovascular disease (CVD), and with the growing number of breast cancer survivors, a better understanding of the risk of CVD in this group is crucial. Studies show that women surviving breast cancer have an increased risk of CVD morbidity and CVD-specific mortality compared with women without breast cancer. $^{2}{ }^{3}$ Moreover, among breast cancer survivors, CVD-related mortality is becoming more common than breast cancer-specific mortality. ${ }^{4}$ This is attributable to improvements in breast cancer survival due to early detection by screening programmes and improved treatments. ${ }^{67}$ Additionally, cardiotoxic effects of breast cancer therapy play a role. ${ }^{89}$ Further, survivors are typically older than the general population and may be more likely to develop CVD because of risk factors common to both cancer and CVD. ${ }^{10}$

Evidence suggests ethnic inequalities in the prognosis of breast cancer with a higher risk of 
breast cancer-specific and overall mortality among some ethnic minority groups. ${ }^{11} 12$ However, although ethnic variation in cardiovascular outcomes in the general population exists, ${ }^{13} 14$ the evidence among patients with breast cancer is limited. Data from the USA show that African American women with breast cancer had an increased risk of dying from CVD compared with white American patients with breast cancer. ${ }^{4}$ However, ethnic compositions and the national context vary across countries and, to our knowledge, no European study has examined the risk of CVD-related outcomes in different ethnic groups among patients with breast cancer. Hence, the aim of this study was to explore differences in overall CVD event, CVD admission and CVD mortality following a diagnosis of breast cancer between the largest ethnic minority groups in the Netherlands compared with ethnic Dutch.

\section{METHODS}

\section{Study sample}

This register-based cohort study builds on data from different Dutch nationwide registers. The registers and linkage procedures used in this cohort study have previously been described in detail. ${ }^{15}$ In brief, we linked data between the national Dutch hospital discharge register, the population register and the cause of death register using a record identification number. This number is assigned to each resident in the Netherlands with a unique combination of birth date, sex and postal code ( $84 \%$ of the Dutch population). The Dutch national hospital discharge register and cause of death register were linked to identify all women with a first admission for breast cancer between 1996 and 2010, using the International Classification of Diseases (ICD) 9th revision and ICD 10th revision. Both patients with invasive (ICD-9: 174 and ICD-10: C50) and in situ breast cancer (ICD-9: 233 and ICD-10: D05) were identified and men were excluded. Data from the population register and the cause of death register were available until 2012 and data from the Dutch hospital discharge register were available until 2010. Individuals were followed from the date of their first breast cancer admission until (1) CVD admission, (2) CVD death, (3) death due to other causes, (4) first emigration or (5) study end (31 December 2012), whichever came first. Linkage of data from the different registers was performed in agreement with the privacy legislation in the Netherlands. All linkages and analysis were performed in a secured environment of Statistics Netherlands. The dataset was made available and analysed in an anonymous form in a secured environment of Statistics Netherlands. Prior to publication, Statistics Netherlands made sure that none of the analysis results showed potential reducibility to the individual level.

\section{Ethnic group}

Ethnic groups were constructed based on the country of birth of the resident and her parents, according to the definition of Statistics Netherlands. ${ }^{16}$ A woman was considered a migrant if she was born abroad or at least one of the parents was born abroad. Women with both parents born in the Netherlands were indicated as being Dutch. The major migrant groups residing in the Netherlands were included which are those born in Turkey, Suriname, Morocco, Indonesia and the Netherlands Antilles.

\section{Outcomes}

CVD admission after a diagnosis of breast cancer was defined as all admissions with either the primary or secondary cause of admission coded as ICD-9: 017.2, 093, 228, 289.1-289.3, 390-459, 557745-747, 780.2, 782.3, 7825, 7826, 785, 786.50-786.59, 789.2, 794.30-794.39. Cardiovascular mortality was defined as dying from a cardiovascular cause after a diagnosis of breast cancer.

Overall cardiovascular event combined the two outcomes and comprised a hospital admission for CVD and/or a death from a cardiovascular cause.

\section{Data analyses}

We first presented baseline characteristics as absolute numbers and percentages according to the ethnic group. Continuous variables were summarised as mean and SD or as median and IQR where appropriate. Subsequently, we calculated HRs and corresponding 95\% CIs using Cox proportional hazard regression analyses to assess ethnic differences in overall cardiovascular events, and separately for hospital admission for CVD and cardiovascular mortality between the ethnic minority groups and the Dutch (reference group) with adjustment for age as a continuous variable, year of admission and type of breast cancer. Cox proportional hazard assumptions were tested by plotting the log minus log functions for the continuous variable age. The assumptions were met in all analyses. All analyses were performed using SPSS V.22.0.

\section{Patient and public involvement}

No patient or public were involved in this study.

\section{RESULTS}

Table 1 presents the characteristics of the study population by the ethnic group. In total, 127714 women with a first admission for breast cancer between 01 January 1996 and 31 December 2010 were included in the study, of which $5 \%$ belonged to an ethnic minority group (table 1 ). Women with more adverse outcomes were in general followed for a shorter period. Among migrants, the Antilleans presented the smallest group and the Indonesians the largest group. In general, the ethnic minority groups were younger than the Dutch population when diagnosed. During follow-up, $19 \%$ of the Dutch population experienced a hospital admission due to CVD, whereas among the ethnic minorities, the proportion of CVD admission ranged from $9 \%$ for Moroccans to $19 \%$ for Surinamese women. A total of 31203 women with breast cancer died during follow-up, of which around $25 \%$ were due to a cardiovascular cause. 
Table 1 Demographic and disease characteristics of women admitted for breast cancer between 1996 and 2010 in the Netherlands according to the ethnic group

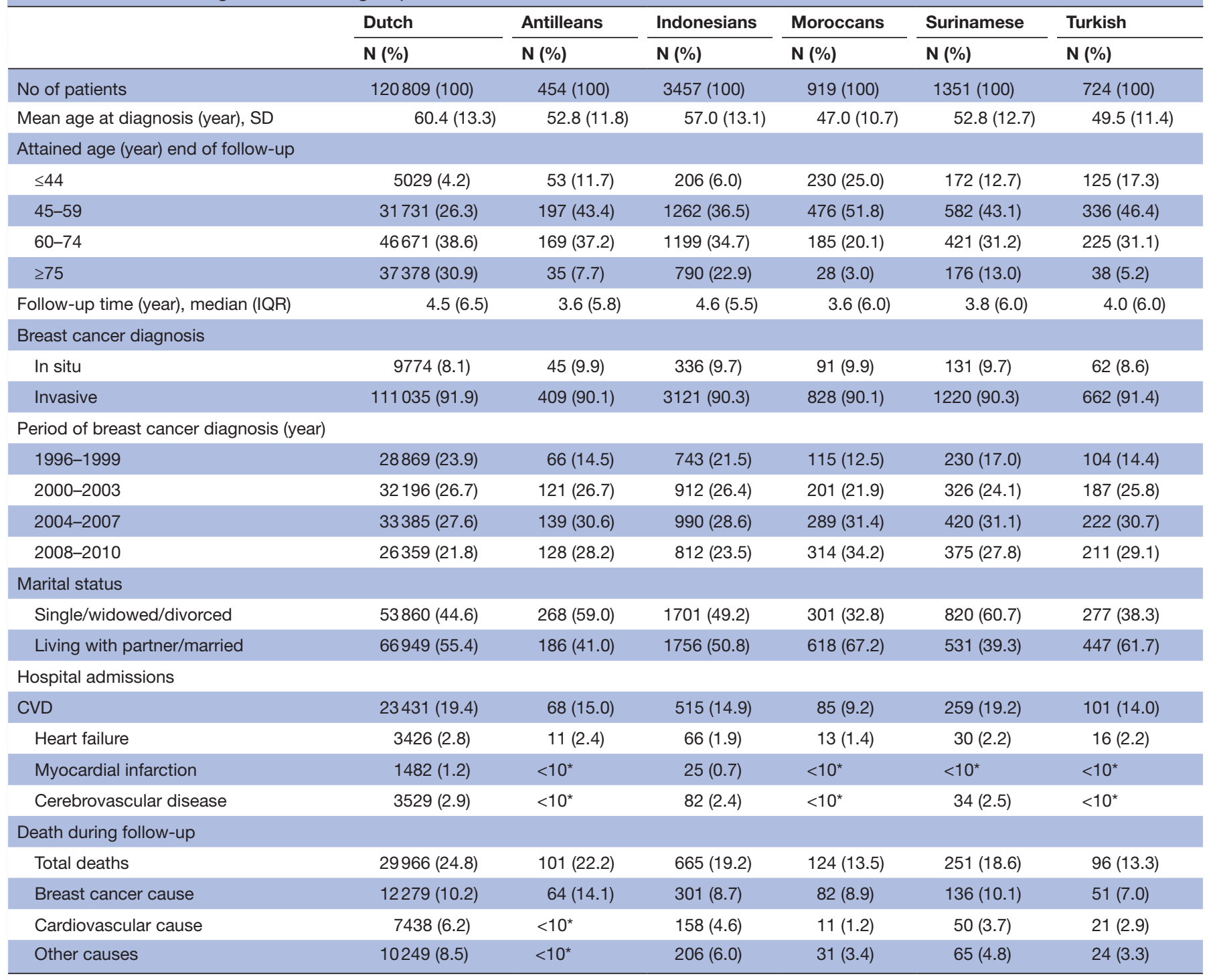

${ }^{*}$ Not given in line with the Dutch data protection guideline as the number of cases was less than 10.

CVD, cardiovascular disease.

Table 2 shows the incidence of a CVD event, which comprises a hospital admission for CVD and/or dying from a cardiovascular cause, among patients with breast

Table 2 Unadjusted and adjusted HRs $(95 \% \mathrm{Cl})$ for a cardiovascular event by the ethnic group

\begin{tabular}{|c|c|c|}
\hline & $\begin{array}{l}\text { Unadjusted } \\
\text { HR (95\% Cl) }\end{array}$ & $\begin{array}{l}\text { Adjusted } \\
\text { HR ( } 95 \% \mathrm{Cl})\end{array}$ \\
\hline \multicolumn{3}{|l|}{ Ethnic group } \\
\hline Dutch & 1.00 (ref.) & 1.00 (ref.) \\
\hline Surinamese & 1.03 (0.92 to 1.16$)$ & 1.46 (1.29 to 1.64$)$ \\
\hline Moroccans & 0.51 (0.42 to 0.63$)$ & $1.01(0.83$ to 1.24$)$ \\
\hline Turkish & 0.71 (0.59 to 0.86$)$ & 1.25 (1.03 to 1.51$)$ \\
\hline Antilleans & 0.83 (0.66 to 1.04$)$ & 1.24 (0.98 to 1.56$)$ \\
\hline Indonesians & $0.76(0.70$ to 0.82$)$ & 0.88 (0.81 to 0.96$)$ \\
\hline
\end{tabular}

Adjusted for age, year of admission and type of breast cancer. cancer by the ethnic group. Compared with Dutch women with breast cancer, both Surinamese (HR 1.46; 95\% CI 1.29 to 1.64 ) and Turkish (HR 1.25; $95 \%$ CI 1.03 to 1.51 ) women with breast cancer had a higher incidence of CVD event after adjustment for breast cancer diagnosis, period of breast cancer diagnosis and age. In contrast, Indonesian women with breast cancer had a significantly lower risk (HR 0.88 ; $95 \%$ CI 0.81 to 0.96 ) of cardiovascular event compared with Dutch women. Although not significant, the Antillean women had a higher incidence of CVD event compared with Dutch women. For Moroccans, there were no differences from Dutch women.

Subsequently, we assessed cardiovascular admission and cardiovascular mortality separately. Table 3 shows the unadjusted and adjusted HRs for a cardiovascular admission. Only women from Suriname had a significantly higher risk (HR 1.45; 95\% CI 1.28 to 1.64 ) of cardiovascular admission compared with Dutch women 


\begin{tabular}{|c|c|c|}
\hline & $\begin{array}{l}\text { Unadjusted } \\
\text { HR (95\% CI) }\end{array}$ & $\begin{array}{l}\text { Adjusted } \\
\text { HR }(95 \% \mathrm{Cl})\end{array}$ \\
\hline \multicolumn{3}{|l|}{ Ethnic group } \\
\hline Dutch & 1.00 (ref.) & 1.00 (ref.) \\
\hline Surinamese & 1.09 (0.96 to 1.23$)$ & 1.45 (1.28 to 1.64$)$ \\
\hline Moroccans & 0.53 (0.43 to 0.66$)$ & $0.92(0.75$ to 1.14$)$ \\
\hline Turkish & 0.76 (0.63 to 0.93$)$ & 1.21 (0.99 to 1.47$)$ \\
\hline Antilleans & $0.89(0.70$ to 1.13$)$ & 1.24 (0.98 to 1.57$)$ \\
\hline Indonesians & 0.75 (0.69 to 0.82$)$ & 0.85 (0.78 to 0.93$)$ \\
\hline
\end{tabular}

Adjusted for age, year of admission and type of breast cancer.

with breast cancer, whereas women from Indonesia had a significantly lower risk of a cardiovascular admission (HR $0.85 ; 95 \% \mathrm{CI} 0.78$ to 0.93 ). The unadjusted and adjusted HRs for cardiovascular mortality for the different ethnic groups are shown in table 4 . The adjusted HRs for cardiovascular mortality were significantly higher for women from Suriname (HR 1.49; 95\% CI 1.13 to 1.97 ) and Turkey (HR 1.96; 95\% CI 1.27 to 3.01), compared with Dutch women, whereas there were no significantly differences between women from Indonesia and Dutch women. For Moroccan and Antillean women, the numbers of deaths due to CVD were too small to perform analyses. In order to determine the impact of breast cancer treatment on the observed differences in CVD outcomes, a sensitivity analysis was performed excluding all women with in situ breast cancer. This did not change the results significantly, suggesting that cancer status and treatment of cancer is not strongly related to CVD outcomes in our study.

\section{DISCUSSION}

\section{Key findings}

In this population-based cohort study of women with breast cancer in the Netherlands, the risk of cardiovascular outcomes varied by the ethnic group. Women from Suriname and Turkey had a higher risk of a CVD event compared with Dutch women with breast cancer. When separating cardiovascular admission and cardiovascular

\begin{tabular}{|c|c|c|}
\hline & $\begin{array}{l}\text { Unadjusted } \\
\text { HR }(95 \% \mathrm{CI})\end{array}$ & $\begin{array}{l}\text { Adjusted } \\
\text { HR }(95 \% \mathrm{Cl})\end{array}$ \\
\hline \multicolumn{3}{|l|}{ Ethnic group } \\
\hline Dutch & 1.00 (ref.) & 1.00 (ref.) \\
\hline Surinamese & 0.70 (0.53 to 0.93$)$ & 1.49 (1.13 to 1.97$)$ \\
\hline Turkish & 0.55 (0.36 to 0.84$)$ & 1.96 (1.27 to 3.01$)$ \\
\hline Indonesians & 0.76 (0.65 to 0.89$)$ & 0.99 (0.84 to 1.16$)$ \\
\hline
\end{tabular}

Adjusted for age, year of admission and type of breast cancer. The number of cardiovascular mortality for the Antilleans and Moroccan women was too low. mortality, Surinamese and Turkish women had a higher risk of both cardiovascular admission and cardiovascular mortality compared with Dutch women, though in Turkish women the results for CVD admission was not significant. In contrast, women from Indonesia with breast cancer had a lower risk of cardiovascular event and cardiovascular admission, but similar risk of cardiovascular mortality compared with ethnic Dutch women with breast cancer. For Moroccan women, the risk of a cardiovascular event did not differ from Dutch women with breast cancer, whereas for Antillean women the risk was not significantly higher.

\section{Discussion of key findings}

Evidence shows that ethnic minority and migrant groups in general have a lower risk of breast cancer compared with the majority population. ${ }^{17} 18$ However, the results of this study indicate that among patients with breast cancer, some ethnic minority groups are disadvantaged in terms of cardiovascular outcomes compared with Dutch women. The results of this study are in line with the sparse evidence on ethnic differences in CVD mortality among patients with breast cancer in the USA which also found some ethnic minority groups to be disadvantaged in terms of cardiovascular mortality. ${ }^{4} 19$ For example, African America women with ductal carcinoma in situ of the breast were found to have a higher risk of CVD death compared with white American women diagnosed with ductal carcinoma in situ of the breast. ${ }^{4}$ However, even though CVDs have been shown to vary by the ethnic group, ${ }^{13}{ }^{20}$ data among patients with breast cancer in Europe have been lacking. Previous European studies on ethnic disparities in breast cancer prognosis have mostly focused on mortality after breast cancer diagnosis, and found that some ethnic minority groups have higher overall and breast cancer-specific mortality. ${ }^{11} 1221$ Our results thereby add a great value to the existing literature by showing that women with breast cancer from Suriname and Turkey are disadvantaged in terms of cardiovascular outcomes compared with Dutch women with breast cancer. The higher incidence of CVD event among Surinamese women with breast cancer reflects the pattern of CVD among Surinamese women in the general Dutch population. Previous studies of the general population in the Netherlands showed that Surinamese women have a higher risk of both acute myocardial infarction (AMI) and stroke compared with Dutch women, ${ }^{22}{ }^{23}$ as well as a higher 5-year CVD mortality after initial admission for CVD. ${ }^{24}$ Turkish women with breast cancer were in the present study found to have a higher incidence of CVD event, compared with Dutch women with breast cancer. However, this only partly reflects on the pattern among Turkish women in the general population in the Netherlands. Previous studies of the general population in the Netherlands did not find differences in the incidence of stroke or AMI among Turkish women compared with the Dutch majority women. ${ }^{22}{ }^{23}$ However, when stratifying on age, a higher incidence of AMI were observed 
in Turkish women aged 50-70 years compared with the Dutch majority women. ${ }^{22}$

The relatively low risk of CVD outcomes among Indonesian women with breast cancer is in contrast to previous studies of the general Dutch population that found no differences in incidence of AMI and a slightly higher risk of stroke among Indonesians compared with Dutch women. ${ }^{22}{ }^{23}$ The reasons for the better CVD prognosis among Indonesian patients with breast cancer are unclear. However, Indonesians are well integrated into the Dutch society with respect to language and culture and have similar income levels and are employed at equal rates as the Dutch general population. ${ }^{25}$ This possibly results in better access to healthcare services than other minority groups and may underlie the better cardiovascular health outcomes among Indonesian women with breast cancer.

Possible explanations for the higher risk of cardiovascular events among Surinamese and Turkish patients with breast cancer may include disparities in access to healthcare services and a high-risk factor burden among these ethnic minorities in the Netherlands. Regular health visits are important for early diagnosis of risk factors that can lead to CVD progression and it is possible that differences in health service utilisation may contribute to the observed ethnic differences in CVD risk among patients with breast cancer. Evidence on healthcare utilisation among patients with breast cancer is scarce, but previous evidence of the general population in the Netherlands suggests that some ethnic minority populations use more general practitioner care than Dutch people do, but that they are less likely to use specialised care. ${ }^{26}$ Moreover, ethnic differences in use of cardiac rehabilitation and lower adherence to medication therapy have been shown. ${ }^{27-30}$ A Danish study found that immigrants from Pakistan and Turkey did not receive adequate medical treatment with beta-blockers after a first AMI compared with Danish-born residents. ${ }^{28}$ In addition, in the Netherlands, Surinamese people have been found to have poor blood pressure control compared with their Dutch counterparts. ${ }^{30}$

The relatively high incidence of CVD admission and mortality among Turkish, Surinamese and Antillean breast cancer women may be explained by the high prevalence of cardiovascular risk factors in these populations. The current study lacked information on CVD risk factors and we were therefore not able to address the possible contribution of these to the observed ethnic differences. However, previous studies of Surinamese and Turkish populations in the Netherlands showed that hypertension, diabetes mellitus and obesity are more common among these populations compared with the Dutch general population. ${ }^{30-33}$ As an example, a previous Dutch study showed that the prevalence of hypertension, the leading risk factor for CVD worldwide, was higher in both Turkish and Surinamese people than in Dutch people. ${ }^{30}$ A previous study found that Antillean women have higher risk of certain CVD risk factors then Dutch women. ${ }^{34}$ Further, since Antilleans resemble other ethnic groups who have been found to have higher risk of some CVD risk factors, such as Surinamese women with African background, this might be the case for Antillean women as well and suggests the need for further studies among this population in the Netherlands. In addition, a study from the USA found that African American patients with breast cancer have higher prevalence of certain CVD risk factors, such as hypertension, diabetes and obesity, prior to initiating aromatase inhibitory therapy, compared with white American patients with breast cancer of the same age. ${ }^{35}$ Although the ethnic groups are not directly comparable, this may also be the case for some of the ethnic groups in the current study, such as the African Surinamese and Antillean women. Evidence suggests that the presence of CVD risk factors among patients with breast cancer at diagnosis is a strong predictive factor for the development of cardiovascular damage associated with breast cancer therapy. ${ }^{36}$ The higher risk factor burden in some ethnic minority groups may therefore contribute to the higher incidence of CVD in these groups.

Additionally, since the risk of CVD has been shown to vary according to breast cancer therapy ${ }^{9}{ }^{37}$ the observed differences may be explained by variation in the treatment received by different ethnic groups. In the current study, data on treatment were not available. However, studies from the USA and UK have reported that ethnic minority women were more likely to receive chemotherapy, which was largely explained by more advanced stage and higher grade tumours. ${ }^{38} 39$

Our findings have important clinical and public health implications because identifying patients with breast cancer who are most vulnerable to cardiovascular outcomes is important in order to guide strategies among patients with breast cancer. The findings suggest the need to increase attention for these women in the cardiovascular risk factor management guidelines in the Netherlands and awareness of the observed ethnic differences in the risk of cardiovascular outcomes among patients with breast cancer should be raised among clinicians and incorporated into oncology practices. The observed differences suggest the need for further studies to identify factors explaining these differences. More specific, studies addressing the potential contribution of both CVD risk factors and type of treatment to the observed ethnic differences found in this study are needed. This will help to tailor appropriate public health and clinical interventions to improve outcomes among patients with breast cancers most at risk of adverse CVD outcomes.

\section{Strength and limitations}

The strength of the current study is the validity of the registers, the linkage methods and the lack of selection of the cohorts. A high validity of both the Dutch National Hospital Discharge Register and the Dutch Population Register has been demonstrated. In a random sample of the Hospital Discharge Register, $99 \%$ of the personal, admission and discharge data and $84 \%$ of the principal diagnoses (validated 
through medical record review by medical specialists) were correctly registered.$^{40}$ In addition, over $97 \%$ of the uniquely linked hospital admissions resulting from linkage of the Hospital Discharge Register with the Population Register were shown to be correctly linked. ${ }^{41}$

Nonetheless, some limitations must be considered. First, although the study is based on a nationwide cohort of patients with breast cancer, absolute numbers are somewhat small when divided into different ethnic groups. Consequently, the numbers were too small to investigate different kinds of CVD, which could have afforded a more nuanced picture. Second, inherent to many national-level databases, we lack detailed data on CVD risk factors, such as smoking, alcohol, cholesterol and obesity, and therefore, we were unable to do additional analyses to assess the contribution of these to the observed ethnic differences. However, we were able to shed light on the potential contributing risk factors to the observed differences due to previous studies on ethnic differences in risk factors in the Netherlands. ${ }^{30-33}$ Additionally, the study lack data on treatment of breast cancer. Since, CVD risk has been shown to vary according to type of treatment, ${ }^{9}{ }^{37}$ adjustment for treatment would have been preferable in order to assess the potential impact of differences in treatment to the observed ethnic differences in CVD. Finally, as in numerous studies, the classifications of the various ethnic groups were based on country of birth. Country of birth may reflect ethnicity reasonably well among some ethnic groups but is likely to be an unreliable proxy measure of ethnicity for other groups such as Surinamese. ${ }^{16}$ The results may be generalised to other European settings with similar healthcare services and composition of ethnic groups.

\section{CONCLUSION}

The results of the current study suggest that the risk of CVD-related outcomes among patients with breast cancer vary by ethnicity. Surinamese and Turkey patients with breast cancer experienced a higher risk, whereas Indonesian patients had a slightly lower risk of CVD event compared with their Dutch counterparts. More extensive cohort studies are needed to identify the forms of CVD that are most common in these groups as well as the potential factors contributing to these differences.

\section{Author affiliations \\ ${ }^{1}$ Department of Public Health, Academic Medical Center, University of Amsterdam, Amsterdam, The Netherlands \\ ${ }^{2}$ Section of Immigrant Medicine, Department of Infectious Diseases, Copenhagen University Hospital, Copenhagen, Denmark \\ ${ }^{3}$ Julius Center for Health Sciences and Primary Care, University Medical Center Utrecht, Utrecht, The Netherlands \\ ${ }^{4}$ Danish Research Centre for Migration, Ethnicity and Health, Section of Health Services Research, Department of Public Health, University of Copenhagen, Copenhagen, Denmark}

Contributors LD, JB, IV, MLB, MN and CA were involved in the study design. LD and $C A$ wrote the paper. JB analysed the data. JB, IV, MLB and MN critically revised the manuscript. All authors approved the final version of the manuscript.
Funding This work was supported by the Dutch Heart Foundation (grant number 2010B296).

Competing interests None declared.

Patient consent Not required.

Provenance and peer review Not commissioned; externally peer reviewed.

Data sharing statement No additional data are available.

Open access This is an open access article distributed in accordance with the Creative Commons Attribution Non Commercial (CC BY-NC 4.0) license, which permits others to distribute, remix, adapt, build upon this work non-commercially, and license their derivative works on different terms, provided the original work is properly cited, appropriate credit is given, any changes made indicated, and the use is non-commercial. See: http://creativecommons.org/licenses/by-nc/4.0/.

\section{REFERENCES}

1. Allemani C, Weir HK, Carreira H, et al. Global surveillance of cancer survival 1995-2009: analysis of individual data for 25,676,887 patients from 279 population-based registries in 67 countries (CONCORD-2). Lancet 2015;385:977-1010.

2. Armenian $\mathrm{SH}, \mathrm{Xu} \mathrm{L}, \mathrm{Ky} \mathrm{B}$, et al. Cardiovascular disease among survivors of adult-onset cancer: a community-based retrospective cohort study. J Clin Oncol 2016;34:1122-30.

3. Bradshaw PT, Stevens J, Khankari N, et al. Cardiovascular disease mortality among breast cancer survivors. Epidemiology 2016;27:6-13.

4. Berkman A, F Cole B, Ades PA, et al. Racial differences in breast cancer, cardiovascular disease, and all-cause mortality among women with ductal carcinoma in situ of the breast. Breast Cancer Res Treat 2014;148:407-13.

5. Patnaik JL, Byers T, DiGuiseppi C, et al. Cardiovascular disease competes with breast cancer as the leading cause of death for older females diagnosed with breast cancer: a retrospective cohort study. Breast Cancer Res 2011;13:R64.

6. Berry DA, Cronin KA, Plevritis SK, et al. Effect of screening and adjuvant therapy on mortality from breast cancer. $N$ Engl J Med 2005;353:1784-92.

7. Myers ER, Moorman P, Gierisch JM, et al. Benefits and harms of breast cancer screening: a systematic review. JAMA 2015;314:1615-34.

8. Darby SC, Ewertz M, McGale P, et al. Risk of ischemic heart disease in women after radiotherapy for breast cancer. $N$ Engl J Med 2013;368:987-98.

9. Thavendiranathan P, Abdel-Qadir H, Fischer HD, et al. Breast Cancer Therapy-Related Cardiac Dysfunction in Adult Women Treated in Routine Clinical Practice: A Population-Based Cohort Study. J Clin Oncol 2016;34:2239-46. JCO.

10. Weaver KE, Foraker RE, Alfano CM, et al. Cardiovascular risk factors among long-term survivors of breast, prostate, colorectal, and gynecologic cancers: a gap in survivorship care? J Cancer Surviv 2013;7:253-61.

11. Møller H, Henson $\mathrm{K}$, Lüchtenborg M, et al. Short-term breast cancer survival in relation to ethnicity, stage, grade and receptor status: national cohort study in England. Br J Cancer 2016;115:1408-15.

12. Latif F, Helgeland J, Bukholm G, et al. Ethnicity differences in breast cancer stage at the time of diagnosis in Norway. Scand J Surg 2015;104:248-53.

13. van Oeffelen AA, Vaartjes I, Stronks K, et al. Incidence of acute myocardial infarction in first and second generation minority groups: does the second generation converge towards the majority population? Int J Cardiol 2013;168:5422-9.

14. Bhopal RS, Bansal N, Fischbacher CM, et al. Ethnic variations in heart failure: Scottish Health and Ethnicity Linkage Study (SHELS). Heart 2012;98:468-73.

15. Koek HL, de Bruin A, Gast A, et al. Incidence of first acute myocardial infarction in the Netherlands. Neth $\mathrm{J}$ Med 2007;65:434-41.

16. Stronks K, Kulu-Glasgow I, Agyemang C. The utility of 'country of birth' for the classification of ethnic groups in health research: the Dutch experience. Ethn Health 2009;14:255-69.

17. Arnold M, Aarts MJ, Siesling S, et al. Diverging breast and stomach cancer incidence and survival in migrants in The Netherlands, 19962009. Acta Oncol 2013;52:1195-201.

18. Gathani T, Ali R, Balkwill A, et al. Ethnic differences in breast cancer incidence in England are due to differences in known risk factors for the disease: prospective study. Br J Cancer 2014;110:224-9. 
19. Solanki PA, Ko NY, Qato DM, et al. Risk of cancer-specific, cardiovascular, and all-cause mortality among Asian and Pacific Islander breast cancer survivors in the United States, 1991-2011. Springerplus 2016:5:82.

20. Hempler NF, Larsen FB, Nielsen SS, et al. A registry-based follow-up study, comparing the incidence of cardiovascular disease in native Danes and immigrants born in Turkey, Pakistan and the former Yugoslavia: do social inequalities play a role? BMC Public Health 2011;11:662

21. Copson E, Maishman T, Gerty S, et al. Ethnicity and outcome of young breast cancer patients in the United Kingdom: the POSH study. Br J Cancer 2014;110:230-41.

22. van Oeffelen AA, Agyemang C, Stronks K, et al. Incidence of first acute myocardial infarction over time specific for age, sex, and country of birth. Neth J Med 2014;72:20-7.

23. Agyemang $\mathrm{C}$, van Oeffelen AA, Norredam M, et al. Ethnic disparities in ischemic stroke, intracerebral hemorrhage, and subarachnoid hemorrhage incidence in the Netherlands. Stroke 2014;45:3236-42.

24. Agyemang C, Vaartjes I, Bots ML, et al. Risk of death after first admission for cardiovascular diseases by country of birth in The Netherlands: a nationwide record-linked retrospective cohort study. Heart 2009;95:747-53

25. Ho L, Bos V, Kunst AE. Differences in cause-of-death patterns between the native Dutch and persons of Indonesian descent in the Netherlands. Am J Public Health 2007;97:1616-8.

26. Stronks K, Ravelli AC, Reijneveld SA. Immigrants in the Netherlands: equal access for equal needs? J Epidemiol Community Health 2001;55:701-7.

27. Cortés $\mathrm{O}$, Arthur HM. Determinants of referral to cardiac rehabilitation programs in patients with coronary artery disease: a systematic review. Am Heart J 2006;151:249-56.

28. Hempler NF, Diderichsen F, Larsen FB, et al. Do immigrants from Turkey, Pakistan and Yugoslavia receive adequate medical treatment with beta-blockers and statins after acute myocardial infarction compared with Danish-born residents? A register-based follow-up study. Eur J Clin Pharmacol 2010;66:735-42.

29. Feder G, Crook AM, Magee P, et al. Ethnic differences in invasive management of coronary disease: prospective cohort study of patients undergoing angiography. BMJ 2002;324:511-6.
30. Agyemang C, Kieft S, Snijder MB, et al. Hypertension control in a large multi-ethnic cohort in Amsterdam, The Netherlands: the HELIUS study. Int J Cardiol 2015;183:180-9.

31. Ujcic-Voortman JK, Schram MT, Jacobs-van der Bruggen MA, et al. Diabetes prevalence and risk factors among ethnic minorities. Eur $J$ Public Health 2009;19:511-5.

32. Bindraban NR, van Valkengoed IG, Mairuhu G, et al. Prevalence of diabetes mellitus and the performance of a risk score among Hindustani Surinamese, African Surinamese and ethnic Dutch: a cross-sectional population-based study. BMC Public Health 2008;8:271.

33. Ujcic-Voortman JK, Bos G, Baan CA, et al. Obesity and body fat distribution: ethnic differences and the role of socio-economic status. Obes Facts 2011;4:53-60.

34. El Fakiri F, Bruijnzeels MA, Foets MME, et al. Different distribution of cardiovascular risk factors according to ethnicity: a study in a high risk population. J Immigr Minor Health 2008;10:559-65.

35. Gallicchio L, Calhoun C, Riseberg D, et al. Cardiovascular health among black and white breast cancer patients initiating aromatase inhibitor therapy. Breast J 2017;23:e23-e31.

36. Maurea N, Coppola C, Ragone G, et al. Women survive breast cancer but fall victim to heart failure: the shadows and lights of targeted therapy. J Cardiovasc Med 2010;11:861-8.

37. Bowles EJ, Wellman R, Feigelson HS, et al. Risk of heart failure in breast cancer patients after anthracycline and trastuzumab treatment: a retrospective cohort study. J Natl Cancer Inst 2012;104:1293-305

38. Jack RH, Davies EA, Møller H. Breast cancer incidence, stage, treatment and survival in ethnic groups in South East England. $\mathrm{Br} J$ Cancer 2009;100:545-50.

39. Killelea BK, Yang VQ, Wang S-Y, et al. Racial differences in the use and outcome of neoadjuvant chemotherapy for breast cancer: results from the national cancer data base. $J$ Clin Oncol 2015;33:4267-76.

40. Paas G, Veenhuizem K. Research on the validity of the $L M R$ (in Dutch), Prismant, 2002.

41. De Bruin A, Kardaun J, Gast F, et al. Record linkage of hospital discharge register with population register : experiences at Statistics Netherlands. Stat J UN Econ Comm Eur 2004;21:23-32. 